\title{
Vascular Endothelial Cadherin Expression in Lung Specimens of Patients with Sepsis-Induced Acute Respiratory Distress Syndrome and Endothelial Cell Cultures
}

\author{
Martina C. Herwig a Michael Tsokos ${ }^{c}$ M. Iris Hermanns ${ }^{d}$ C. James Kirkpatrick ${ }^{d}$ \\ Annette M. Müller ${ }^{b}$ \\ ${ }^{a}$ Division of Ophthalmic Pathology, Department of Ophthalmology, and ${ }^{\mathrm{b}}$ Department of Pediatric Pathology, \\ University of Bonn, Bonn, 'Institute of Legal Medicine and Forensic Sciences, Charité-University Medicine Berlin, \\ Berlin, and ${ }^{\mathrm{d}}$ Institute of Pathology, University Medical Center, Johannes Gutenberg University, Mainz, Germany
}

\section{Key Words}

Acute respiratory distress syndrome $\cdot$ Cadherin $\cdot$ Cell cultures · Endothelium $\cdot$ Human lung $\cdot$ Vascular endothelial cadherin · Vessel type

\begin{abstract}
Aims: Vascular endothelial (VE) cadherin is a cell adhesion molecule localized at endothelial cell (EC) junctions. As a major component of endothelial adherens junctions, its main function is the maintenance and regulation of EC integrity. In the acute respiratory distress syndrome (ARDS), increased vascular permeability is a major mechanism in pulmonary edema and lung dysfunction. In this study, VEcadherin expression was investigated in ARDS lungs and control tissue as well as in an ARDS cell culture model. Methods: Lung specimens of patients with ARDS due to Gramnegative sepsis ( $n=20$; control lung tissue: $n=41$ ) and cell cultures of human pulmonary microvascular ECs and human umbilical vein ECs stimulated with LPS, TNF- $\alpha$ and IFN- $\gamma$ were stained with a VE-cadherin antibody. Staining intensity was semiquantitatively evaluated by conventional light and immunofluorescence microscopy. Results: VE-cadherin expression was statistically significantly reduced in the en-
\end{abstract}

dothelium of all vessel types in ARDS lungs compared to control tissue. Cell cultures showing disrupted cellular borders confirmed these results. Conclusion: Reduced expression of VE-cadherin has to be considered as a major mechanism of increased vessel permeability in ARDS. The previously described vessel-type-specific expression pattern of VE-cadherin in the human lung is not influenced by ARDS.

Copyright $\odot 2013$ S. Karger AG, Basel

\section{Introduction}

Vascular endothelial (VE)-cadherin (cadherin-5) is a calcium-dependent cell-cell adhesion molecule exclusively located at endothelial intercellular junctions. First described in 1990 [1], its main function is the maintenance and regulation of the endothelial barrier via cellcell adhesion $[2,3]$.

In vitro studies and animal models have shown that loss and reduction of VE-cadherin at endothelial cell (EC) junctions result in a reduced endothelial integrity with an increased endothelial permeability allowing inflammatory cells to migrate from blood vessels into the tissue [4-6]. VE-cadherin expression is diminished by different

\section{KARGER}

E-Mail karger@karger.com

www.karger.com/pat
(C) 2013 S. Karger AG, Basel

1015-2008/13/0805-0245\$38.00/0
Prof. Dr. Med. Annette M. Müller

Department of Pediatric Pathology, University of Bonn

Sigmund-Freud-Strasse 25

DE-53127 Bonn (Germany)

E-Mail annette.mueller@ukb.uni-bonn.de 
factors such as cytokines, e.g. tumor necrosis factor (TNF)- $\alpha$ and interferon (IFN)- $\gamma$, nuclear transcription factors such as HMGB1 (high-mobility group box1) and lipopolysaccharide (LPS) [7-9] that play a major role in the sepsis-induced acute respiratory distress syndrome (ARDS). ARDS is an acute lung injury caused by different agents, including Gram-negative bacteria in sepsis.

The main pulmonary issue in ARDS is a failure of the semipermeable endothelial barrier between blood and interstitial space, leading to increased endothelial permeability with interstitial and later alveolar edema. Microvascular ECs play a key role in the disruption of the blood vessel barrier leading to leukocyte infiltration and release of proinflammatory cytokines [10]. The transmission of leukocytes as one of the main components in ARDS pathogenesis is driven by upregulation of several molecules that also induce changes in cell-cell adhesion, thus indicating the central role of adhesion molecules. The release of proteolytic and inflammatory mediators by leukocytes supports an increased endothelial permeability via junctional proteins such as VE-cadherin resulting eventually in the breakdown of the endothelial barrier $[11,12]$.

In previous studies, vessel-type-specific VE-cadherin expression was described and strong endothelial expression was noted in arteries, arterioles and capillaries in contrast to statistically significantly weaker expression in veins and venules [13]. As the endothelium and its function is critical to the vascular leak syndrome and subsequent shock that is associated with mortality in septic patients [12], the influence of septic ARDS on VE-cadherin expression in different vessel types was investigated in lung tissue and in suitable in vitro models. As there are currently no published pathomorphological studies comparing endothelial VE-cadherin expression in human lungs and EC cultures with regard to sepsis-induced ARDS, this is - to our knowledge - the first study examining these aspects and emphasizing the role of increased pulmonary vascular permeability in this disease.

\section{Materials and Methods}

\section{Lung Tissue}

Material

Formalin-fixed paraffin-embedded samples of 61 patients were examined for VE-cadherin expression. All ARDS patients $(n=20)$ died of documented multiorgan failure due to microbiologically proven Gram-negative sepsis defined in accordance with the criteria of the American College of Chest Physicians/the Society of Critical Care Medicine [14]. The presence of at least two of the internationally accepted clinical signs of sepsis in the medical his- tory [15] as well as pathologically proven macro- and microscopic signs of ARDS were required in this study. The control tissue was recruited from tumor-free parts (with regular lung morphology) of lobectomy specimens harboring a malignant lung tumor $(\mathrm{n}=$ 41). Informed consent signed by the patient or their relatives was obtained in all cases.

The lung specimens were divided into two subgroups: The ARDS group ( $\mathrm{n}=20 ; 13$ men, age range: $1-83$ years; 7 women, age range: $27-74$ years) and the control group $(\mathrm{n}=41 ; 20 \mathrm{men}$, age range: $34-75$ years; 21 women, age range: $33-74$ years).

The presence of all five vessel types (arteries, arterioles, capillaries, venules and veins) as well as morphological signs of manifest ARDS were determined histologically after hematoxylin-eosin and Elastica-van-Gieson staining. The identification of vessel types was carried out by the analysis of histomorphologic characteristics in serial slides. For small vessels (arterioles and venules), the vessels were identified by tracing them back to larger vessels from which they originated or into which they were discharging. The reactivity of the endothelium in ARDS specimens $(n=20)$ was shown by immunohistochemical staining for CD31 that is constantly expressed in all vessel types of regular lung tissue and ARDS-altered tissue [16].

\section{Methods}

Staining of VE-cadherin has been described previously [13]. In brief, the paraffin-embedded formalin-fixed specimens were stained using the avidin-biotin complex immunoperoxidase technique. The specimens were incubated with VE-cadherin antibody (1:100, anti-VE-cadherin, mouse IgG1; BD Biosciences) for $60 \mathrm{~min}$ followed by a $30-\mathrm{min}$ incubation with the secondary antibody (1:200, biotinylated horse anti-mouse IgG; BA-2000, Vector). The color reaction was performed with 3,3-diaminobenzidine.

A semiquantitative analysis of the intensity of the VE-cadherin immunoreaction was performed using a $10 \times 10$ grid at $\times 100$ magnification, scoring the intensity of endothelial staining in 20 defined fields $\left(2 \mathrm{~mm}^{2}\right)$. A score based on the internationally accepted immunoreactivity score was employed to interpret staining intensity [17]. The immunoreaction was graded from 0 to $3: 0=$ no staining; $1=$ weak staining; $2=$ moderate staining, and $3=$ strong staining $[18,19]$. For each specimen, the staining intensity was evaluated independently by two examiners (M.C.H. and A.M.M.). The mathematical mean for each of the five different vessel types was calculated. The VE-cadherin staining intensity in the ARDS and control groups was compared by multivariate analysis (general linear model) with respect to the different vessel types. A value of $\mathrm{p}<0.05$ was defined as statistically significant. Statistical analyses were performed with SPSS (version 18.0).

\section{Cell Cultures}

Cell Culture and Isolation

Human pulmonary microvascular ECs (HPMEC), which served as a model for the lung microvasculature, were isolated from macro- and microscopically normal portions of lung specimens surgically resected from adult patients who had undergone lobectomy for early-stage lung cancer (Department of Pathology and Surgery, Johannes Gutenberg University, Mainz, Germany). HPMEC cells were isolated and cultured according to a slightly modified method of Wagner et al. [20] as described before [21]. 


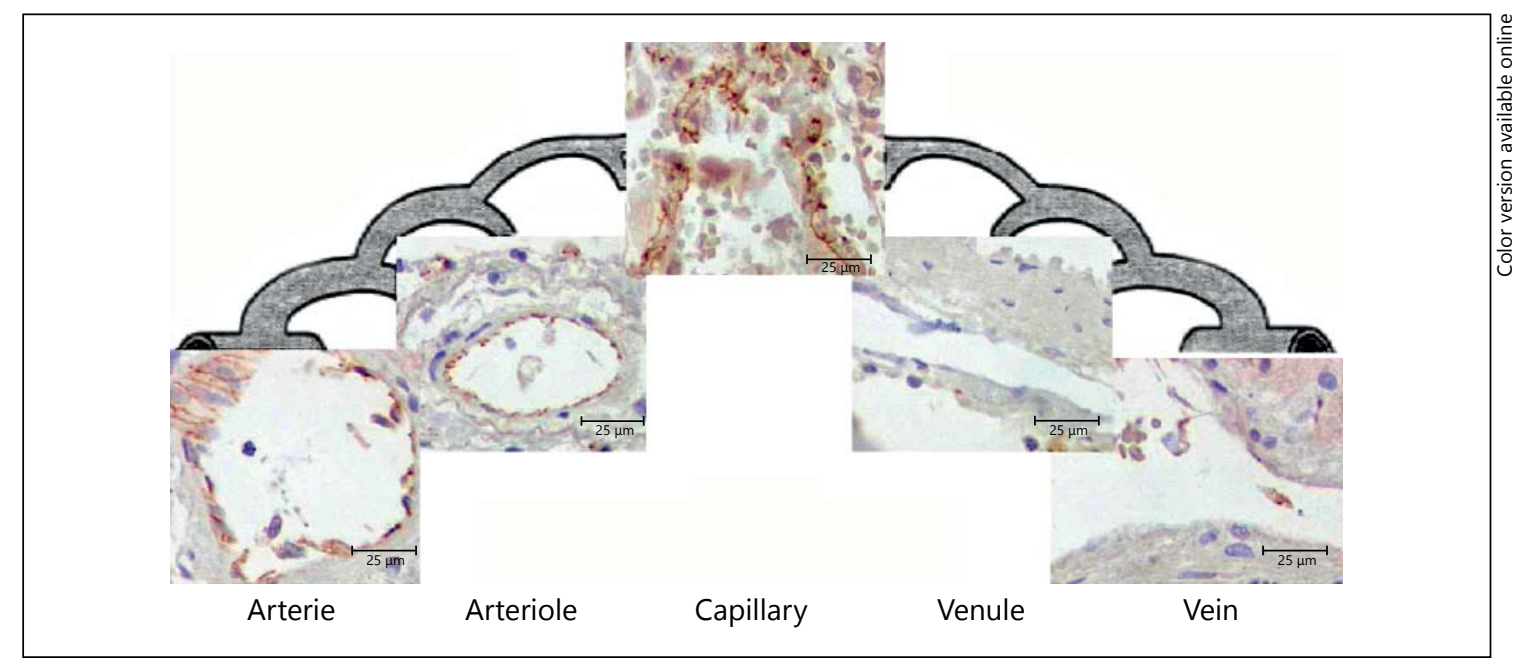

Fig. 1. Weak endothelial expression of VE-cadherin in ARDS-altered lungs [control specimens are displayed in ref. 13].

Human umbilical vein ECs (HUVEC), which served as a model for the macrovasculature, were isolated from umbilical cord veins by collagenase perfusion and cultured according to Jaffe [22] with minor modifications [23] as described previously [21].

Exposure to TNF- $\alpha$, LPS and IFN- $\gamma$

Cultures were exposed to TNF- $\alpha$, LPS, IFN- $\gamma$ or TNF- $\alpha$ plus IFN- $\gamma$ on day 7 for a further 4 and $24 \mathrm{~h}$, respectively. A volume of $1 \mathrm{ml} \mathrm{TNF- \alpha}(30,150$ and $300 \mathrm{U} / \mathrm{ml})$, LPS $(1 \mu \mathrm{g} / \mathrm{ml})$, IFN- $\gamma$ $(10 \mathrm{ng} / \mathrm{ml})$ and TNF- $\alpha$ plus IFN- $\gamma$ (TNF- $\alpha 300 \mathrm{U} / \mathrm{ml}+$ IFN- $\gamma$ $10 \mathrm{ng} / \mathrm{ml}$ ) was applied to the cell cultures. As a control (unstimulated cell cultures), one well of each slide was exposed to culture medium without additives.

Immunocytochemical Staining

For immunocytochemical staining, the cells were fixed with paraformaldehyde (3.7\%) in CS buffer (0.1 M PIPES, 1 mM EGTA, $4 \%$ polyethylene glycol $800,0.1 \mathrm{M} \mathrm{NaOH}$ ) for $20 \mathrm{~min}$ and washed twice in PBS. The filter membranes were further permeabilized with $0.5 \%$ Triton X-100 in PBS. The primary antibody against VEcadherin (mouse anti-human, BD Transduction Laboratories, Heidelberg, Germany) was added and incubated with the cells overnight at $4^{\circ} \mathrm{C}$ and afterwards incubated with a fluorochromecoupled secondary antibody for $3 \mathrm{~h}$. The secondary antibody (Molecular Probes, MoBiTec, Göttingen, Germany) was conjugated with Alexa Fluor 488 (green fluorescence).

Staining intensity and cell morphology were analyzed by scoring the intensity of endothelial staining in 4 defined fields using a score from 0 to 3 :

' 0 ' = loss of EC coherence; 1 = weak staining intensity with damage of EC coherence; 2 = medium staining intensity with interrupted EC coherence and a few gaps, and $3=$ strong staining intensity with intact EC coherence.

The staining intensity of positively stained ECs and the morphology of the cell coherence were graded twice by one examiner (M.C.H.). The examiner was blinded with respect to the source of the specimen, and mathematical means and medians were calculated to identify the staining intensity for the unstimulated and stimulated cell cultures.

\section{Results}

\section{Lung Tissue}

In all 41 control lung specimens, there was a statistically significant $(\mathrm{p}<0.005)$ heterogeneous vessel-typespecific expression pattern of VE-cadherin, as described before. Capillary, arterial and arteriolar ECs (median: 2.03-1.77) displayed the strongest staining intensity, while the endothelium of veins and venules (median: $0.36-0.53)$ displayed fairly weak expression $(\mathrm{p}<0.005)$.

In the 20 specimens of the ARDS patients, VE-cadherin staining was generally weaker, with a median of 0.55-0.37 for arteries, arterioles and capillaries, and 0.04 for veins and venules (fig. 1-3). However, the vessel-type-specific expression pattern (fig. 2; table 1) with a high VE-cadherin expression in arteries, arterioles and capillaries, and a weak expression in veins and venules - was maintained. These results were statistically significant $(\mathrm{p}<0.05)$. Age $(\mathrm{p}=0.4)$ and gender $(\mathrm{p}=0.8)$ did not have any influence on VE-cadherin expression.

Homogenous expression of CD31 was found in all vessel types of ARDS-altered lungs confirming the reliability of the reduced VE-cadherin antigen expression in ARDS lungs. 
Fig. 2. Arteriolar endothelial expression of VE-cadherin (brown in the online version) in control lung tissue and ARDS-altered lungs. There is a strong (brown in the online version) staining in arteriolar EC junctions of control tissue (a). In contrast, the arteriole in the ARDS-altered lung specimen exhibits weaker antigen expression (b).

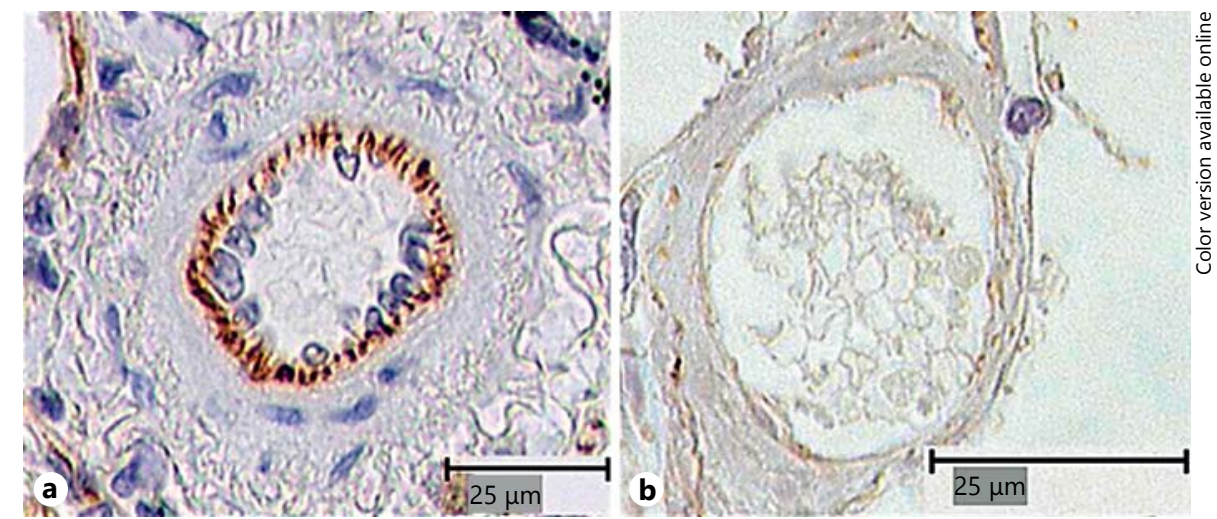

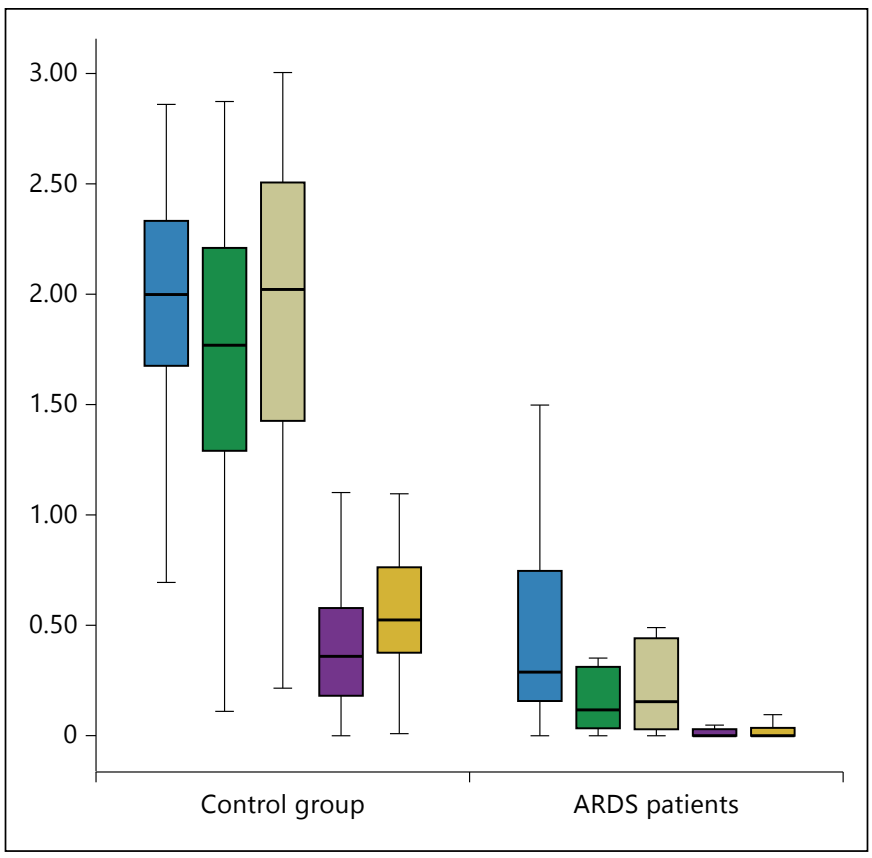

Fig. 3. Expression of VE-cadherin in lung specimens from controls and ARDS-altered lungs with a statistically significant reduction in VE-cadherin expression especially in arteries and arterioles. 1 = Arteries; 2 = arterioles; 3 = capillaries; 4 = venules; 5 = veins.

Table 1. Median vessel type staining intensity in lung tissue of ARDS patients and controls

\begin{tabular}{lll}
\hline & ARDS & Control \\
\hline Arteries & 0.55 & 2.00 \\
Arterioles & 0.37 & 1.77 \\
Capillaries & 0.44 & 2.03 \\
Venules & 0.04 & 0.36 \\
Veins & 0.04 & 0.53 \\
\hline
\end{tabular}

\section{Cell Cultures}

Unstimulated cell cultures (HPMEC and HUVEC) revealed a homogeneous EC multilayer with strong circumferential antigen expression of VE-cadherin on the cellcell contact areas (fig. $4 \mathrm{a}, \mathrm{b}$; table 2). In cultures stimulated with LPS, TNF- $\alpha$ or IFN- $\gamma$, gaps were present along the intercellular adhesion zone leading to discontinuous cell-cell connections (fig. 4c, d). VE-cadherin expression was weak and fragmented.

There was no difference in the intensity of VE-cadherin expression with regard to the different factors: LPS, IFN- $\gamma$ or TNF- $\alpha$ (table 2). Different concentrations of TNF- $\alpha$ also did not influence staining intensity. Double stimulation with TNF- $\alpha$ und IFN- $\gamma$ led to an increased gap formation. However, this observation was not statistically significant.

\section{Discussion}

VE-Cadherin Antigen Expression in Lung Tissue from the Control Group and ARDS-Altered Lung Tissue

All 61 lung specimens showed a vessel-type-specific antigen expression of VE-cadherin indicating strong expression in arteries, arterioles and capillaries in comparison to only weak expression in venules and veins, as described previously [13]. In contrast, lung tissue with signs of ARDS $(n=20)$ displayed a statistically significant reduction in VE-cadherin expression in all vessel types while the vessel type-specific expression pattern was maintained.

VE-cadherin as key component of the endothelial adherens junction is important for the maintenance and regulation of the endothelial barrier $[2,24]$. Our in situ results support this finding. Thus, a significant reduc- 
Fig. 4. Endothelial VE-cadherin expression in unstimulated cell cultures of HP$\operatorname{MEC}(\mathbf{a})$ and HUVEC (b) and LPS-stimulated HPMEC (c) and HUVEC (d). Unstimulated cells show intense staining at the cell borders in contrast to stimulated cell cultures, which display jagged VE-cadherin expression with many gaps after $4 \mathrm{~h}$ of stimulation.
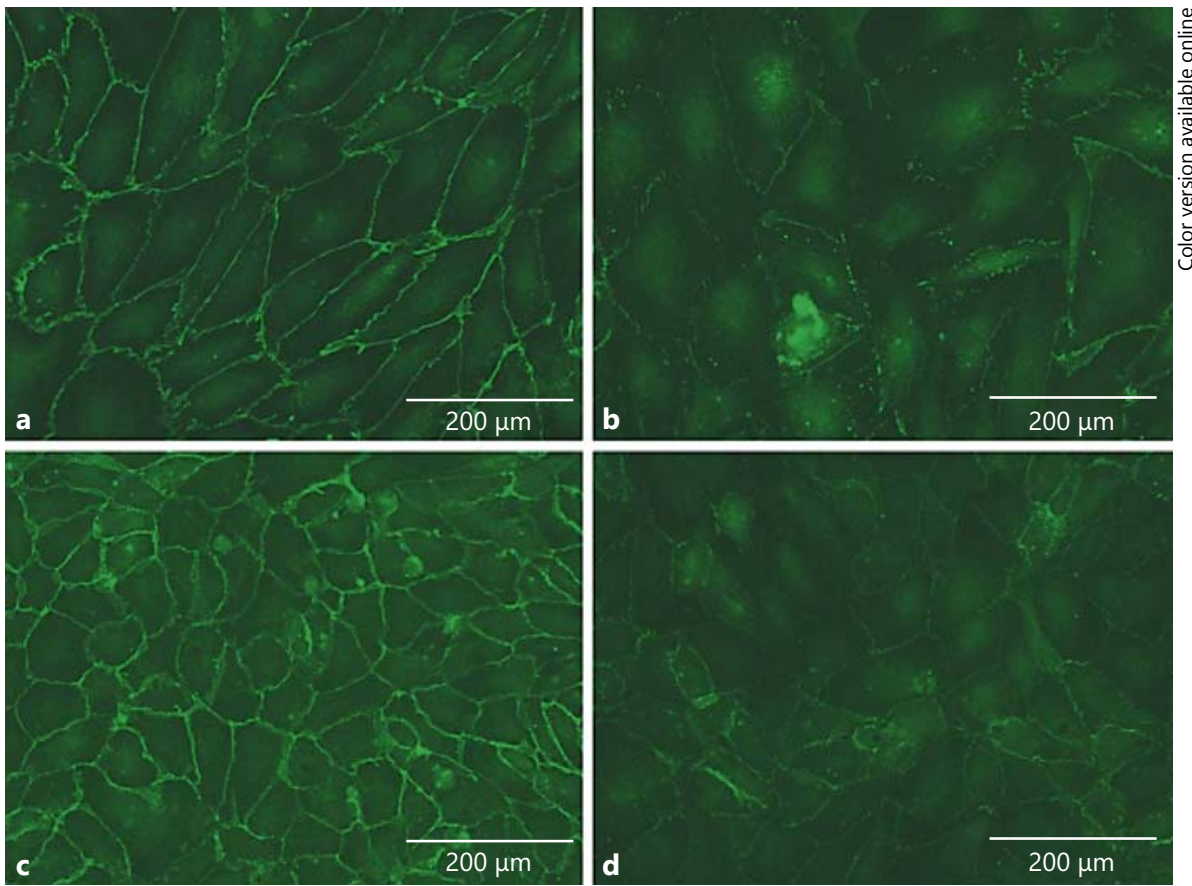

Table 2. VE-cadherin antigen expression in HPMEC and HUVEC after stimulation with LPS, IFN- $\gamma$ and TNF- $\alpha$ for 4 and 24 h revealing reduced antigen expression compared to unstimulated cell cultures

\begin{tabular}{llllllll}
\hline & unstimulated & LPS & IFN- $\gamma$ & IFN- $\gamma /$ TNF- $\alpha$ & 30 U/ml TNF- $\alpha$ & 150 U/ml TNF- $\alpha$ & 300 U/ml TNF- $\alpha$ \\
\hline HPMEC: $4 \mathrm{~h}$ & 2.23 & 1.4 & 1.56 & 1.27 & 1.61 & 1.59 & 1.7 \\
HPMEC: $24 \mathrm{~h}$ & 2.63 & 1.58 & 1.71 & 1.69 & 1.61 & 1.89 & 1.99 \\
HUVEC: $4 \mathrm{~h}$ & 2.36 & 1.62 & 1.28 & 1.33 & 1.6 & 1.56 \\
HUVEC: $24 \mathrm{~h}$ & 2.49 & 1.93 & 1.22 & 0.81 & 1.46 & 1.44 & 1.49 \\
\hline
\end{tabular}

tion in VE-cadherin at EC junctions results in increased vessel permeability leading to edema and extravasation of leukocytes [25]. Furthermore, our results are in accordance with those of Zhang et al. [26]. Several factors such as cytokines and LPS contribute to a decreased VE-cadherin expression $[4,12]$. In addition, matrix metalloproteinases have also been associated with decreased VE-cadherin expression [26]. Extravasated leukocytes are also able to reduce VE-cadherin expression via elastase-mediated proteolysis [11] and VE-cadherin itself seems to regulate neutrophil recruitment [27]. Carden et al. [11] as well as Zhang et al. [26] found a significant increase in soluble VE-cadherin in the blood plasma of ARDS patients compared to healthy control patients, which was explained by cleavage of VE-cad- herin in ARDS. In other diseases and models that are somewhat comparable to septic ARDS, disruption of VE-cadherin also led to an increase in vascular permeability [28, 29].

These observations correlate with our in situ results of diminished VE-cadherin expression in lung vessels of ARDS patients.

\section{VE-Cadherin Expression in Unstimulated and}

Stimulated Cell Cultures (HPMEC and HUVEC)

In unstimulated cell cultures, VE-cadherin antigen expression was homogeneous at EC junctions, as described previously by several authors [3]. In stimulated cell cultures, VE-cadherin expression was, in accordance with other studies $[3,7-9,30]$, reduced and gaps were 
present at the cell junctions. In contrast to our results, some studies state that TNF- $\alpha$ alone (or together with neutrophils) is unable to induce an increase in endothelial permeability and a decrease in VE-cadherin expression [6,31]. Referring to the duration of TNF- $\alpha-$ stimulation, Del Maschio et al. [6] did not find any difference between TNF- $\alpha$ stimulation for 4,6 or $20 \mathrm{~h}$. In contrast, Wojciak-Stothard et al. [9] described an interendothelial gap formation $15 \mathrm{~min}$ after the addition of TNF- $\alpha$. However, in the study by Del Maschio et al. [6] and in our own study VE-cadherin expression was investigated after $4 \mathrm{~h}$ of TNF- $\alpha$ stimulation. Wong et al. [8] showed a statistically nonsignificant dose-dependent endothelial reaction after double stimulation with IFN- $\gamma$ plus TNF- $\alpha$. We made similar observations, even though no statistically significant difference was found. Bannerman et al. [7] found increased endothelial permeability after $2 \mathrm{~h}$ of LPS stimulation that increased with time. We did not investigate VE-cadherin expression during the first $4 \mathrm{~h}$ of stimulation. However, the length of stimulation did not have any significant influence on VE-cadherin expression in our study ( 4 and $24 \mathrm{~h}$ ). Bogatcheva et al. [10] were also able to demonstrate a visible reduction in VE-cadherin/ZO-1 on EC junctions after LPS stimulation. They concluded that the gap formation in the EC layer after LPS treatment correlated with the increasing deficit in the VE-cadherin/ZO-1 peripheral localization.

Via the Toll-like receptor 4, LPS may lead to tyrosine phosphorylation of zonula adherens molecules such as VE-cadherin leading to opening of the endothelial paracellular pathway [32].

In contrast, Birukova et al. [30] investigated iloprostinduced VE-cadherin accumulation. In a model in which VE-cadherin transinteractions are blocked, they found that VE-cadherin may control EC barrier enhancement and recovery via the Rac pathway.

Permeability measurements showed an LPS-induced increased permeability in rat mesenteric postcapillary venules in vivo and a barrier breakdown in human dermal microvascular ECs in vitro accompanied by the development of large intercellular gaps with fragmented VE-cadherin immunostaining [33]. In an in vitro flow model, the role of VE-cadherin in real-time gap formation for leukocyte transmigration was observed [34].

As EC exposure to cytokines like TNF- $\alpha$, IFN- $\gamma$ and LPS plays a central role in the pathogenesis of sepsis and ARDS leading to the destruction of the contiguous structure via the development of gaps and reduced VE-cadherin expression, these observations seem to be related to impaired barrier function in ARDS $[7,8,35]$. There are several studies on adherens junction complex disruption and therapeutic interventions by these cytokines at VEcadherin level as this is nowadays regarded as a key mechanism leading to microvascular permeability $[4,10,36]$. Therefore, comparing the in vitro results with our in situ observations, our cell culture model seems to be suitable for investigating the influence of ARDS on VE-cadherin expression, although the fact that HPMEC are a mixture of arteriolar, venular and capillary ECs presents a limitation. This is promising since specimens from patients with ARDS are very limited due to ethical reasons. Furthermore, the use of primary isolated HPMEC as a cell culture model will allow further studies on other VE-cadherin interactions, such as the enhancement of the pulmonary endothelial barrier, e.g. by iloprost, as described by Birukova et al. [30].

In conclusion, the reduced EC adhesion in ARDS can be - at least in part - attributed to decreased VE-cadherin expression in human lung tissue of ARDS patients and corresponding cell culture models. Thus, the reduced VE-cadherin expression has to be regarded as one of the factors responsible for increased permeability and enhanced leukocyte transmigration during ARDS. Furthermore, comparisons of in situ and in vitro observations revealed that the HPMEC cell culture model proves to be suitable for further investigation of the interactions of VE-cadherin with other adherens junction components.

\section{Acknowledgments}

The authors thank Dr. Stefan Lange, Department of Biomedicine, Ruhr University Bochum, Germany, for statistical advice.

References

\footnotetext{
1 Heimark RL, Degner M, Schwartz SM: Identification of a $\mathrm{Ca}^{2+}$-dependent cell-cell adhesion molecule in endothelial cells. J Cell Biol 1990;110:1745-1756.

2 Dejana E, Bazzoni G, Lampugnani MG: Vascular endothelial (VE)-cadherin: only an intercellular glue? Exp Cell Res 1999;252:1319.

-3 Lampugnani MG, Resnati M, Raiteri M, Pigott R, Pisacane A, Houen G, Ruco LP, Dejana E: A novel endothelial-specific membrane protein is a marker of cell-cell contacts. J Cell Biol 1992;118:1511-1522.

4 Sawant DA, Tharakan B, Adekanbi A, Hunter FA, Smythe WR, Childs EW: Inhibition of VE-cadherin proteasomal degradation attenuates microvascular hyperpermeability. Microcirculation 2011;18:46-55.
} 
5 Hermant $\mathrm{B}$, Bibert $\mathrm{S}$, Concord E, Dublet $\mathrm{B}$, Weidenhaupt M, Vernet T, Gulino-Debrac D: Identification of proteases involved in the proteolysis of vascular endothelium cadherin during neutrophil transmigration. J Biol Chem 2003;278:14002-14012.

6 Del Maschio A, Zanetti A, Corada M, Rival Y, Ruco L, Lampugnani MG, Dejana E: Polymorphonuclear leukocyte adhesion triggers the disorganization of endothelial cell-to-cell adherens junctions. J Cell Biol 1996;135:497510.

7 Bannerman DD, Sathyamoorthy M, Goldblum SE: Bacterial lipopolysaccharide disrupts endothelial monolayer integrity and survival signaling events through caspase cleavage of adherens junction proteins. J Biol Chem 1998;273:35371-35380.

8 Wong RK, Baldwin AL, Heimark RL: Cadherin-5 redistribution at sites of TNF-alpha and IFN-gamma-induced permeability in mesenteric venules. Am J Physiol 1999;276:H736 H748.

9 Wojciak-Stothard B, Entwistle A, Garg R, Ridley AJ: Regulation of TNF-alpha-induced reorganization of the actin cytoskeleton and cell-cell junctions by Rho, Rac, and Cdc42 in human endothelial cells. J Cell Physiol 1998; 176:150-165.

10 Bogatcheva NV, Zemskova MA, Kovalenkov Y, Poirier C, Verin AD: Molecular mechanisms mediating protective effect of cAMP on lipopolysaccharide (LPS)-induced human lung microvascular endothelial cells (HLMVEC) hyperpermeability. J Cell Physiol 2009; 221:750-759.

-11 Carden D, Xiao F, Moak C, Willis BH, Robinson-Jackson S, Alexander S: Neutrophil elastase promotes lung microvascular injury and proteolysis of endothelial cadherins. Am J Physiol 1998;275:H385-H392.

12 Lee WL, Slutsky AS: Sepsis and endothelial permeability. N Engl J Med 2010;363:689-691.

$\checkmark 13$ Herwig MC, Muller KM, Muller AM: Endothelial VE-cadherin expression in human lungs. Pathol Res Pract 2008;204:725-730.

14 American College of Chest Physicians/Society of Critical Care Medicine Consensus Conference: Definitions for sepsis and organ failure and guidelines for the use of innovative therapies in sepsis. Crit Care Med 1992;20: 864-874.

15 Ventetuolo CE, Levy MM: Sepsis: a clinical update. Clin J Am Soc Nephrol 2008;3:571577.
Muller AM, Hermanns MI, Skrzynski C, pression of the endothelial markers PECAM-1, vWf, and CD34 in vivo and in vitro. Exp Mol Pathol 2002;72:221-229.

17 Remmele W, Hildebrand U, Hienz HA, Klein PJ, Vierbuchen M, Behnken LJ, Heicke B, Scheidt E: Comparative histological, histochemical, immunohistochemical and biochemical studies on oestrogen receptors, lectin receptors, and Barr bodies in human breast cancer. Virchows Arch A Pathol Anat Histopathol 1986;409:127-147.

18 Muller AM, Gruhn KM, Herwig MC, Tsokos M: VE-cadherin and ACE: markers for sepsis in post mortem examination? Leg Med (Tokyo) 2008;10:257-263.

19 Herwig MC: VE-Cadherin in humanen Lungen mit septisch bedingtem ARDS und endothelialen Zellkulturen; thesis, Ruhr University Bochum, 2006.

20 Wagner M, Hermanns I, Bittinger F, Kirkpatrick CJ: Induction of stress proteins in human endothelial cells by heavy metal ions and heat shock. Am J Physiol 1999;277:L1026-L1033.

21 Muller AM, Hermanns MI, Cronen C, Kirkpatrick CJ: Comparative study of adhesion molecule expression in cultured human macro- and microvascular endothelial cells. Exp Mol Pathol 2002;73:171-180.

22 Jaffe EA, Nachman RL, Becker CG, Minick CR: Culture of human endothelial cells derived from umbilical veins. Identification by morphologic and immunologic criteria. J Clin Invest 1973;52:2745-2756.

23 Kirkpatrick CJ, Bultmann BD, Gruler H: Interaction between enteroviruses and human endothelial cells in vitro. Alterations in the physical properties of endothelial cell plasma membrane and adhesion of human granulocytes. Am J Pathol 1985;118:15-25.

24 Wolfson RK, Chiang ET, Garcia JG: HMGB1 induces human lung endothelial cell cytoskeletal rearrangement and barrier disruption. Microvasc Res 2011;81:189-197.

25 Hordijk PL, Anthony E, Mul FP, Rientsma R, Oomen LC, Roos D: Vascular-endothelialcadherin modulates endothelial monolayer permeability. J Cell Sci 1999;112:1915-1923.

26 Zhang RY, Liu YY, Li L, Cui W, Zhao KJ, Huang WC, Gu XW, Liu W, Wu J, Min D, Mao EQ, Tang YQ: Increased levels of soluble vascular endothelial cadherin are associated with poor outcome in severe sepsis. J Int Med Res 2010;38:1497-1506.

27 Orrington-Myers J, Gao X, Kouklis P, Broman M, Rahman A, Vogel SM, Malik AB: Regulation of lung neutrophil recruitment by VE-cadherin. Am J Physiol Lung Cell Mol Physiol 2006;291:L764-L771.
28 Gillrie MR, Krishnegowda G, Lee K, Buret AG, Robbins SM, Looareesuwan S, Gowda DC, Ho M: Src-family kinase dependent disruption of endothelial barrier function by Plasmodium falciparum merozoite proteins. Blood 2007;110:3426-3435.

29 Geny B, Khun H, Fitting C, Zarantonelli L, Mazuet C, Cayet N, Szatanik M, Prevost MC, Cavaillon JM, Huerre M, Popoff MR: Clostridium sordellii lethal toxin kills mice by inducing a major increase in lung vascular permeability. Am J Pathol 2007;170: 1003-1017.

30 Birukova AA, Tian Y, Dubrovskyi O, Zebda N, Sarich N, Tian X, Wang Y, Birukov KG: VEcadherin trans-interactions modulate Rac activation and enhancement of lung endothelial barrier by iloprost. J Cell Physiol 2012;227: 3405-3416.

-31 Friedl J, Turner E, Alexander HR Jr: Augmentation of endothelial cell monolayer permeability by hyperthermia but not tumor necrosis factor: evidence for disruption of vascular integrity via VE-cadherin down-regulation. Int J Oncol 2003;23:611-616.

32 Gong P, Angelini DJ, Yang S, Xia G, Cross AS, Mann D, Bannerman DD, Vogel SN, Goldblum SE: TLR4 signaling is coupled to SRC family kinase activation, tyrosine phosphorylation of zonula adherens proteins, and opening of the paracellular pathway in human lung microvascular endothelia. J Biol Chem 2008; 283:13437-13449.

33 Schlegel N, Baumer Y, Drenckhahn D, Waschke J: Lipopolysaccharide-induced endothelial barrier breakdown is cyclic adenosine monophosphate dependent in vivo and in vitro. Crit Care Med 2009;37:1735-1743.

34 Shaw SK, Bamba PS, Perkins BN, Luscinskas FW: Real-time imaging of vascular endothelial-cadherin during leukocyte transmigration across endothelium. J Immunol 2001;167: 2323-2330.

35 Angelini DJ, Hyun SW, Grigoryev DN, Garg P, Gong P, Singh IS, Passaniti A, Hasday JD, Goldblum SE: TNF-alpha increases tyrosine phosphorylation of vascular endothelial cadherin and opens the paracellular pathway through fyn activation in human lung endothelia. Am J Physiol Lung Cell Mol Physiol 2006;291:L1232-L1245.

36 Xing J, Birukova AA: ANP attenuates inflammatory signaling and Rho pathway of lung endothelial permeability induced by LPS and TNFalpha. Microvasc Res 2010;79:56-62. 